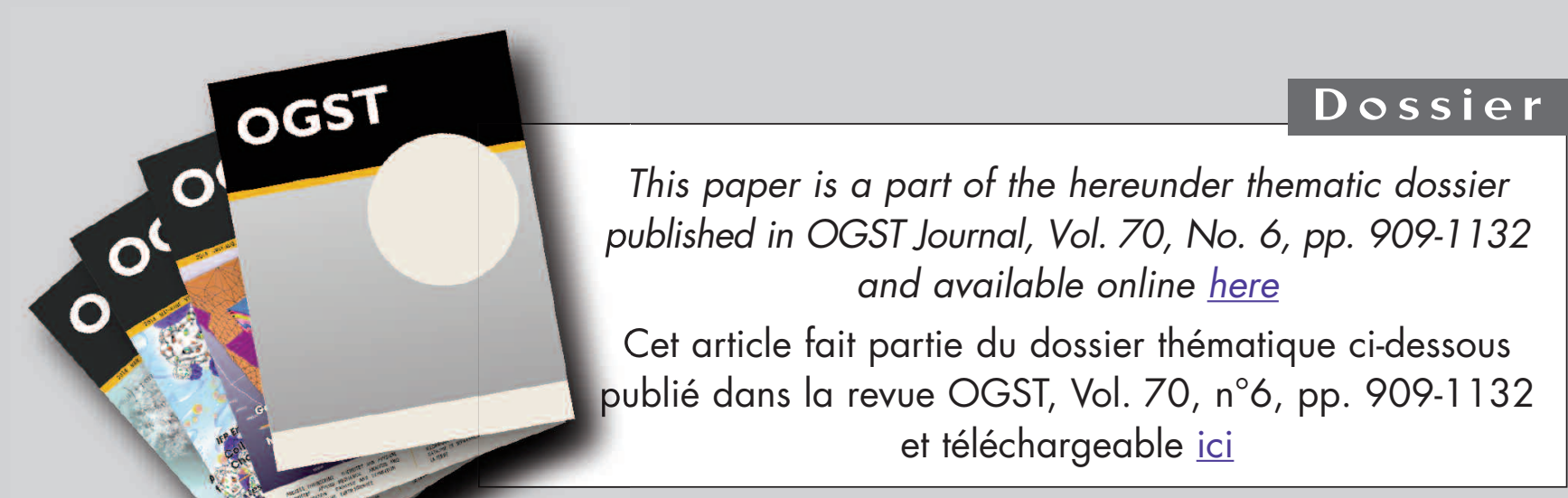

Oil \& Gas Science and Technology - Rev. IFP Energies nouvelles, Vol. 70 (2015), No. 6, pp. 909-1132

Copyright (C) 2015, IFP Energies nouvelles

909 > Editorial - Enhanced Oil Recovery (EOR), Asphaltenes and Hydrates Éditorial - EOR «récupération assistée du pétrole», Asphaltènes et Hydrates D. Langevin and F. Baudin

\section{ENHANCED OIL RECOVERY (EOR)}

917 > HP-HT Drilling Mud Based on Environmently-Friendly Fluorinated Chemicals Boues de forage HP/HT à base de composés fluorés respectueux de I'environnement

I. Henaut, D. Pasquier, S. Rovinetti and B. Espagne

931 > Effective Viscosity in Porous Media and Applicable Limitations for Polymer Flooding of an Associative Polymer

Viscosité effective dans des médias poreux et limites d'application de l'injection de polymères associatifs

P. Zhang, Y. Wang, Y. Yang, W. Chen and S. Bai

$941>$ Dynamic Gelation of HPAM/Cr(III) under Shear in an Agitator and Porous Media Gélification dynamique de HPAM/Cr(III) sous cisaillement dans un agitateur et en milieu poreux

Y. Haiyang, W. Yefei, Z. Jian, L. Peng and S. Shenglong

$951>$ Computer Modeling of the Displacement Behavior of Carbon Dioxide in Undersaturated Oil Reservoirs

Modélisation par ordinateur du comportement de déplacement du dioxyde de carbone dans des réservoirs d'huile non saturés

B. Ju, Y.S. Wu and J. Qin

$967>$ Predicting CO, Minimum Miscibility Pressure (MMP) Using Alternating Conditional Expectation (ACE) Algorithm

Prédiction de la pression miscibilité minimum (MMP) du CO en utilisant un algorithme basé sur l'ACE (Alternating Conditional Expectation)

0 . Alomair, A. Malallah, A. Elsharkawy and M. Iqbal

983 > Towards the Development of Bitumen Carbonates: An Integrated Analysis of Grosmont Steam Pilots

Vers le développement des carbonates bitumineux : une analyse intégrée des pilotes vapeur de Grosmont

C.C. Ezeuko, J. Wang, M.S. Kallos and I.D. Gates

1007> A Novel Model of Foam Flooding Considering Multi-Factors for Enhancing Oil Recovery

Un nouveau modèle d'injection de mousse considérant de multiples facteurs afin d'améliorer la récupération de pétrole

J. Wang, H. Liu, H. Zhang, G. Zhang, P. Liu and K. Sepehrnoori
1025> Testing of Snorre Field Foam Assisted Water Alternating Gas (FAWAG) Performance in New Foam Screening Model

Vérification des performances de la méthode FAWAG (Foam Assisted Water Alternating Gas) sur le champ de Snorre, en Norvège, avec un nouveau modèle de sélection des mousses

P. Spirov and S. Rudyk

\section{ASPHALTENES}

1035> Structural Study of Asphaltenes from Iranian Heavy Crude Oil Étude structurale d'asphaltènes de pétrole brut lourd iranien L. Davarpanah, F. Vahabzadeh and A. Dermanaki

$1051>$ Experimental Study and Mathematical Modeling of Asphaltene Deposition Mechanism in Core Samples

Étude expérimentale et modélisation mathématique du mécanisme de déposition d'asphaltène dans des carottes de forage

T. Jafari Behbahani, C. Ghotbi, V. Taghikhani and A. Shahrabadi

1075> Prediction of the Gas Injection Effect on the Asphaltene Phase Envelope Prévision Prévision de l'effet d'injection de gaz sur l'enveloppe de phase des asphaltènes P. Bahrami, R. Kharrat, S. Mahdavi and H. Firoozinia

\section{HYDRATES}

1087> Methane Hydrate Formation and Dissociation in the Presence of Silica Sand and Bentonite Clay

Formation et dissociation d'hydrates de méthane en présence de sable de silice et d'argile de bentonite

V. Kumar Saw, G. Udayabhanu, A. Mandal and S. Laik

$1101>$ Prediction of Mass Flow Rate in Supersonic Natural Gas Processing Prédiction du débit massique dans les applications de traitement supersonique du gaz naturel

C. Wen, X. Cao, Y. Yang and Y. Feng

$1111>$ Experimental Study on Hydrate Induction Time of Gas-Saturated Water-in-Oil Emulsion using a High-Pressure Flow Loop

Étude expérimentale sur le temps d'induction d'hydrate d'une émulsion eau-enhuile saturée en gaz en utilisant une boucle à circulation sous haute pression X.F. Lv, B.H. Shi, Y. Wang, Y.X. Tang, L.Y. Wang and J. Gong

1125> Hollow Silica: A Novel Material for Methane Storage La silice creuse : un nouveau matériau pour le stockage de méthane V.D. Chari, P.S.R. Prasad and S.R. Murthy 


\title{
Effective Viscosity in Porous Media and Applicable Limitations for Polymer Flooding of an Associative Polymer
}

\author{
Peng Zhang ${ }^{1,2 *}$, Yefei Wang${ }^{2}$, Yan Yang ${ }^{2}$, Wuhua Chen ${ }^{2}$ and Shixun Bai ${ }^{2}$ \\ ${ }^{1}$ Chongqing University of Science \& Technology, School of Chemistry and Chemical Engineering, Chongqing 266555 - China \\ ${ }^{2}$ China University of Petroleum (East China), School of Petroleum Engineering, Qingdao 266555 - China \\ e-mail: zhangpengchina@foxmail.com - wangyf@upc.edu.cn - 491095127@qq.com -578974157@qq.com - orinocoflow@qq.com \\ * Corresponding author
}

\begin{abstract}
Résumé - Viscosité effective dans des médias poreux et limites d'application de l'injection de polymères associatifs - Le polyacrylamide associatif hydrophobe (HAPAM) est considéré comme un candidat prometteur pour l'injection de polymère, de par son excellente capacité apparente de viscosification. Par rapport au polyacrylamide partiellement hydrolysé (HPAM), les facteurs de résistance et de résistance résiduelle causés par le HAPAM sont généralement plus élevés. Cependant, la viscosité effective du HAPAM est plus faible que celle d'un polymère conventionnel pour une concentration de $2000 \mathrm{mg} / \mathrm{L}$. La capacité de rétention dynamique de HAPAM est environ 2,3 fois celle du HPAM. L'efficacité pour déplacer de l'huile avec du HAPAM est plus faible que celle obtenue avec un polymère conventionnel pour une concentration de $2000 \mathrm{mg} / \mathrm{L}$ et pour un modèle de type sandpack homogène. L'efficacité de déplacement de l'huile avec du HAPAM est plus élevée que celle de HPAM uniquement pour un modèle hétérogène (ratio de perméabilité 2,8). Les ratios de perméabilité élevés et faibles ne sont pas bons pour obtenir des déplacements efficaces de l'huile avec du HAPAM.
\end{abstract}

\begin{abstract}
Effective Viscosity in Porous Media and Applicable Limitations for Polymer Flooding of an Associative Polymer - Hydrophobically associating polyacrylamide (HAPAM) is considered to be a promising candidate for polymer flooding because of its excellent apparent viscosifying capability. Compared with partially hydrolyzed polyacrylamide (HPAM), the resistance factor and residual resistance factor caused by HAPAM tend to be higher. However, the effective viscosity of HAPAM is lower than that of conventional polymer at a concentration of $2000 \mathrm{mg} / \mathrm{L}$. The dynamic retention capacity of HAPAM is about 2.3 times that of HPAM. The oil displacement efficiency of HAP AM is lower than that of conventional polymer at a concentration of $2000 \mathrm{mg} / \mathrm{L}$ in the homogeneous sandpack model. The oil displacement efficiency of HAPAM is higher than that of HPAM only in the heterogeneous model (permeability ratio 2.8). Neither high nor low permeability ratios are good for the oil displacement efficiency of HAPAM.
\end{abstract}




\section{INTRODUCTION}

Regarding the use of partially hydrolyzed polyacrylamide (HPAM) for high-temperature and high-salinity reservoirs, there are many unfavorable factors [1] such as thermal oxidation degradation, salt sensitivity and mechanical degradation.

To overcome these weaknesses of HPAM, hydrophobically associating polyacrylamide (HAPAM) has been paid more and more attention [2]. In aqueous solutions, above a critical association concentration, HAPAM has excellent apparent viscosity due to its unique structure. In addition, many research results show HAPAM has some excellent properties such as anti-shear, salt tolerance and temperature resistance [3-5].

Besides the solution properties, many experimental studies have been carried out to evaluate the performance of HAPAM in porous media [6,7]. The main research objectives were usually to determine the resistance factors, retention, residual resistance factors and oil recovery. Many research results [8-10] indicate significantly higher resistance factors and residual resistance factors of HAPAM than those of corresponding HPAM. Maia et al. [10] believe that HAPAM may form agglomerates or associations in porous media. In addition to significant adsorption (multilayer adsorption [11, 12]) and enhanced viscosity, the residual resistance factor of HAPAM is several times greater than that of HPAM. Zhang et al. [13] and Ye et al. [14] reported that HAPAM can generally form aggregates with super-molecular and network structures even in porous media. Based on these results, HAPAM can establish a higher resistance factor and residual resistance factor in porous media. Wang et al. [15] proposed that the resistance factor was used to describe the total effect for reducing aqueous phase fluidity. So, in a sense, the resistance factor reveals a kind of general result. To maintain the effectiveness and persistence of fluid displacement, the residual resistance factor should be reduced in order to increase the effective viscosity in porous media, because the retention should be kept low in order to ensure an in-depth propagation of the viscous polymer slug. The retention will inevitably cause a reduction of the concentration of movable polymer through porous media, which can cause a decrease in effective viscosity, and eventually leads to a decrease in the swept area [15]. However, effective viscosity in porous media is also very important for tertiary oil recovery [16].

Previous experimental work from Buchgraber et al. [17] showed that associative polymer concentrations from $1250 \mathrm{mg} / \mathrm{L}$ to $1500 \mathrm{mg} / \mathrm{L}$ led to the best swept area and recovery results. However, $2500 \mathrm{mg} / \mathrm{L}$ solution led to poor recovery and low sweep efficiency due to very serious pore plugging by multi-layer polymer adsorption. Taylor and Nasr-El-Din [7] pointed out that adsorption was a concern with polymer flooding and has limited this application. On the other hand, the significant adsorption and physical gel properties of HAPAM have been proved to be industrially useful when applied to water shutoff and conformance control [18].

The effective viscosity and dynamic retention capacity of HPAM and HAPAM were studied in this paper. Moreover, the ability to enhance oil recovery of the two types of polymers was also studied in homogeneous and heterogeneous models. The results show that the application of HAPAM in polymer flooding has some limitations.

\section{EXPERIMENT}

\subsection{Materials}

Two types of polyacrylamides were studied in this paper: HPAM (HJ, degree of hydrolysis: $21.2 \%$ [ $\eta]: 2510 \mathrm{~mL} / \mathrm{g}$ ) and HAPAM (SHDH5, degree of hydrolysis: $25.4 \%$ [ $\eta]$ : $2045 \mathrm{~mL} / \mathrm{g}$ ). The synthetic formation water for all the tests was a brine with TSD $=20000 \mathrm{mg} / \mathrm{L}$ (deionized water with $1.861 \mathrm{wt} \%$ sodium chloride and $0.139 \mathrm{wt} \%$ calcium chloride) and viscosity of $1.22 \mathrm{mPa}$.s at $25^{\circ} \mathrm{C}$. The oil sample used in this study was dehydrated oil (asphaltenes $7.8 \%$, resins $33.9 \%$, oily constituents $58.3 \%$ ) from Shengli Oilfield, with viscosity of $56 \mathrm{mPa} . \mathrm{s}$ at $80^{\circ} \mathrm{C}$. The displacement tests were conducted by using artificial cores $(\Phi 2.5 \times 10 \mathrm{~cm})$ and sandpacks $(\Phi 2.5 \times 20 \mathrm{~cm})$ at $80^{\circ} \mathrm{C}$. The petrophysical properties of the artificial cores are summarized in Table 1 .

\subsection{Experimental Procedures}

The seepage experiment to determine the effective viscosity was carried out as follows. The artificial core was dried, weighed and saturated by synthetic water.

TABLE 1

Petrophysical properties of artificial cores

\begin{tabular}{c|c|c|c}
\hline No. & $\begin{array}{c}\text { Porous } \\
\text { volume } \\
(\mathrm{mL})\end{array}$ & $\begin{array}{c}\text { Porosity } \\
(\%)\end{array}$ & $\begin{array}{c}\text { Brine } \\
\text { permeability } \\
\left(\mu \mathrm{m}^{2}\right)\end{array}$ \\
\hline $6-1$ & 7.17 & 29.65 & 0.562 \\
\hline $6-2$ & 7.37 & 30.48 & 0.562 \\
\hline $7-1$ & 7.76 & 32.09 & 0.836 \\
\hline $7-2$ & 7.98 & 33.00 & 0.836 \\
\hline
\end{tabular}


Then, synthetic water was injected into the core at a constant rate of $0.34 \mathrm{~mL} / \mathrm{min}$ until a stable pressure was established. After that, 10 Pore Volumes (PV) of polymer slug were injected. Next, synthetic water was injected until a plateau pressure was obtained again.

Previous research mainly focused on the apparent viscosity of polymer in solution. Actually, effective viscosity can provide more accurate viscosity when polymer solution flows in porous media. Effective viscosity (also called Darcy viscosity) is calculated by Darcy's law (Eq. I), where $\Delta P$ is the pressure drop of $10 \mathrm{PV}$ polymer solution, and $K_{p}$ is the permeability of the polymer solution in the core. However, it should be pointed out that it is difficult to obtain accurate permeability of polymer solution. $K_{p}$ can be approximately replaced by brine permeability $\left(K_{f}\right)$ after polymer injection [15]. So, $\mu_{e f}$ has another expression form (Eq. 2) [15], where $F_{R}$ is the resistance factor, $F_{R R}$ is the residual resistance factor, and $\mu_{w}$ is the water viscosity at the test temperature. $F_{R}$ can be calculated by Equation (3) by the pressure drop of the polymer solution $\left(\Delta P_{P}\right)$ and brine $\left(\Delta P_{B}\right)$ through porous media at the same flow rate. $F_{R R}$ can be obtained by Equation (4) based on $\Delta P_{B}$ and the pressure drop $\left(\Delta P_{F}\right)$ of the brine after polymer injection at the same flow rate:

$$
\begin{gathered}
\mu_{e f}=\frac{K_{p} \Delta P}{v_{D} L} \\
\mu_{e f}=\frac{F_{R}}{F_{R R}} \mu_{w} \\
F_{R}=\frac{\Delta P_{p}}{\Delta P_{B}} \\
F_{R R}=\frac{\Delta P_{F}}{\Delta P_{B}}
\end{gathered}
$$

The experiment to determine the dynamic retention capacity was carried out as follows. The artificial core was dried, weighed and saturated by synthetic water. Then, the polymer solutions $(2000 \mathrm{mg} / \mathrm{L})$ of $\mathrm{HJ}$ and SHDH5 were injected into the cores at a constant rate of $0.34 \mathrm{~mL} / \mathrm{min}$, respectively.

The concentration of polymer solution at the outlet was monitored by the starch-cadmium iodide method until the concentration reached a stable value. Using the material balance method, the retention capacity in porous media can be calculated by Equation (5) [19], where $Q$ is the retention capacity $(\mathrm{mg} / \mathrm{g}), \rho_{0}$ is the concentration of injected polymer solution $(\mathrm{mg} / \mathrm{L}), V_{0}$ is the accumulated injection volume $(\mathrm{mL}), \rho_{i}$ is the outflow concentration of the $i$ th sample $(\mathrm{mg} / \mathrm{L}) . V_{i}$ is the outflow volume of the $i$ th sample $(\mathrm{mL}), n$ is the number of outflow samples, and $W$ is the mass of the dry core:

$$
Q=\left(\rho_{0} V_{0}-\sum_{i=1}^{n} \rho_{i} V_{i}\right) / W
$$

The laboratory oil displacement experiment was carried out as follows. The wet-packed sandpack was flooded with the oil sample until water production ceased. Thereafter, brine flooding continued until the water cut was greater than $98 \%$. After that, $0.3 \mathrm{PV}$ of polymer slug was injected (2 $000 \mathrm{mg} / \mathrm{L})$, followed by water flood until the water cut of the efflux reached $98 \%$ again.

Lyophilization and microscopic observations of polymer solution in porous media were carried out as follows. About $1 \mathrm{PV}$ of polymer solution was injected into the artificial core $(\Phi 25 \times 90 \mathrm{~mm})$. Next, the core was quickly transferred to a vacuum cup of liquid nitrogen and the vacuum cup was placed in a freezer for $24 \mathrm{~h}$ at $-20^{\circ} \mathrm{C}$. Then, the core was put into a lyophilizer for $24 \mathrm{~h}$ with a vacuum pressure of 7-8 $\mathrm{Pa}$. After being freeze-dried, the core was crushed at the inlet and $30-40 \mathrm{~mm}$ away from the inlet and core fragments were examined with a scanning electron microscope.

\section{RESULTS AND DISCUSSION}

\subsection{Seepage Properties and Effective Viscosity}

The artificial cores were injected with polymer solution of $\mathrm{HJ}$ and SHDH5, respectively. As shown in Figure 1,

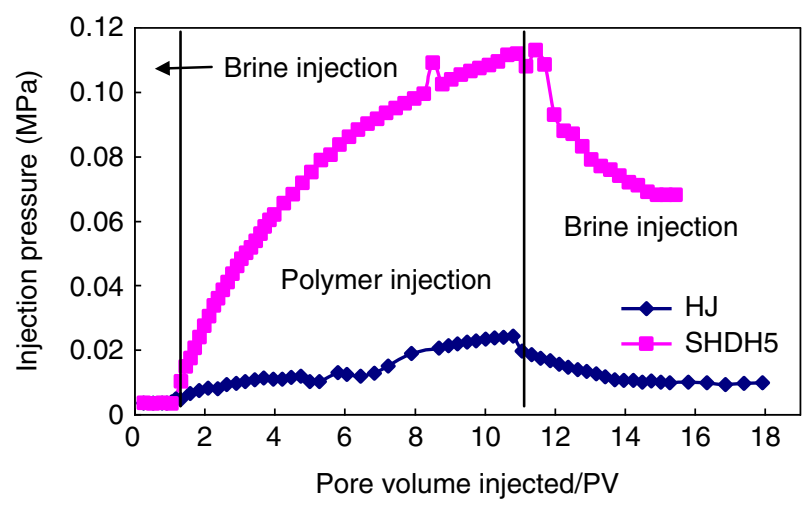

Figure 1

Variation of injection pressures during the injection of the two $2000 \mathrm{mg} / \mathrm{L}$ polymer solutions. 
TABLE 2

The seepage parameters and effective viscosity of the two polymers

\begin{tabular}{|c|c|c|c|c|c|c|c|}
\hline Polymer & $\begin{array}{l}\text { Initial } \\
\text { permeability } \\
\qquad\left(\mu \mathrm{m}^{2}\right)\end{array}$ & Core code & $\begin{array}{l}\text { Injection } \\
\text { pressure of } \\
\text { polymer } \\
\text { flooding } \\
(\mathrm{MPa})\end{array}$ & $\begin{array}{c}\text { Injection } \\
\text { pressure of } \\
\text { subsequent } \\
\text { water flooding } \\
\quad(\mathrm{MPa})\end{array}$ & $F_{R}$ & $F_{R R}$ & $\begin{array}{l}\text { Effective } \\
\text { viscosity } \\
\text { (mPa.s) }\end{array}$ \\
\hline $\mathrm{HJ}$ & \multirow[t]{2}{*}{0.562} & $6-1$ & 0.062 & 0.0201 & 5.743 & 1.875 & 1.11 \\
\hline SHDH5 & & $6-2$ & 0.1918 & 0.108 & 19.636 & 11.157 & 0.64 \\
\hline $\mathrm{HJ}$ & \multirow[t]{2}{*}{0.836} & $7-1$ & 0.024 & 0.0092 & 6.67 & 2.56 & 0.95 \\
\hline SHDH5 & & $7-2$ & 0.1119 & 0.068 & 31.97 & 19.43 & 0.59 \\
\hline
\end{tabular}

the injection pressure of SHDH5 is much higher than that of HJ. Also, the injection pressure of the subsequent water flooding of HAPAM is higher than that of HPAM. The seepage parameters and effective viscosity of the two polymers are shown in Table 2 . The $F_{R R}$ values indicate that the ability to reduce permeability of SHDH5 is higher than that of HJ. However, the strong ability to reduce permeability means an increase in retention loss. The retention capacity of HAPAM may be higher than that of HPAM. It will be demonstrated in the next section. The retention loss would result in a reduction in the amount of movable polymer flowing in porous media, which can cause a decrease in effective viscosity. As shown in Table 2, the effective viscosity of SHDH5 is lower than that of HJ. Under the same conditions, the bulk viscosity of SHDH5 (49.2 mPa.s) is higher than that of $\mathrm{HJ}$ (19.7 mPa.s).

\subsection{Dynamic Retention Capacity}

In order to reveal the reason that HAPAM can build excellent flow resistance in porous media, experiments of dynamic retention capacity were carried out. The relationship between efflux concentration and the pore volume injected is shown in Figure 2. For HPAM, the polymer retention can reach a balance in a short period of time. However, for HAPAM, the injected PV needs to exceed at least 11 before the polymer achieves the concentration balance. According to Equation (5), the result indicates that the dynamic retention capacity of SHDH5 $(1450.98 \mu \mathrm{g} / \mathrm{g})$ is 2.3 times that of HJ $(626.70 \mu \mathrm{g} / \mathrm{g})$. Thus, it can be seen that the high flow resistance of HAPAM is mainly due to high retention. However, could this high flow resistance become an advantage for polymer flooding? The next section may give an answer.

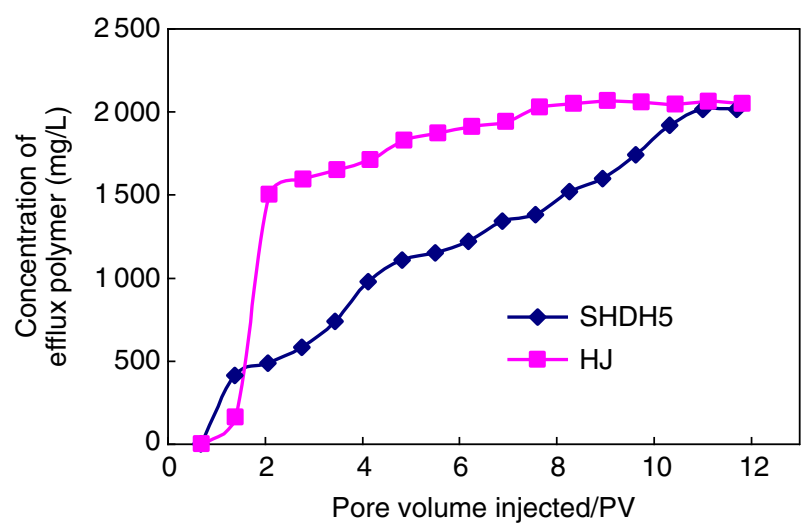

Figure 2

Variation of efflux concentration during the injection of the two $2000 \mathrm{mg} / \mathrm{L}$ polymer solutions (permeability: $1.121 \mu^{2}$ ).

\subsection{Ability to Enhance Oil Recovery}

A series of oil displacement experiments were carried out in homogeneous sandpack models of different permeabilities $\left(0.5-3.0 \mu \mathrm{m}^{2}\right)$. The tertiary recovery of polymer flooding and the final oil recovery of each flood test are shown in Table 3. The oil displacement efficiency of SHDH5 is always lower than that of HJ for different permeabilities at the same concentration of $2000 \mathrm{mg} / \mathrm{L}$. Only when permeability was approximately $1 \mu \mathrm{m}^{2}$ was the tertiary recovery of the two kinds of polymers approximately equivalent, and higher than those with other permeabilities. Low permeability is not favorable for injecting polymer and high permeability may result in fingering of subsequent water flooding. Therefore, there is an optimum permeability for polymer flooding. With permeability of approximately $1.7 \mu \mathrm{m}^{2}$, the curves of polymer flooding of the two kinds of polymers are 
TABLE 3

Summary of polymer flood tests in the homogeneous sandpack model

\begin{tabular}{c|c|c|c|c}
\hline $\begin{array}{c}\text { Permeability } \\
\left(\mu \mathrm{m}^{2}\right)\end{array}$ & Polymer & $\begin{array}{c}\text { Recovery of water flood } \\
(\%)\end{array}$ & $\begin{array}{c}\text { Final oil recovery } \\
(\%)\end{array}$ & 62.3 \\
\hline 0.503 & HJ & 45.5 & 55.3 & 16.8 \\
\hline 0.543 & SHDH5 & 41.9 & 72.1 & 22.6 \\
\hline 0.905 & HJ & 49.5 & 65.5 & 22.2 \\
\hline 0.970 & SHDH5 & 43.3 & 70.3 & 18.4 \\
\hline 1.697 & HJ & 51.9 & 58.1 & 9.7 \\
\hline 1.835 & SHDH5 & 48.4 & 64.6 & 17.3 \\
\hline 2.425 & HJ & 47.3 & 53.3 & 14.9 \\
\hline 2.514 & SHDH5 & 38.4 & 77.3 & 16.5 \\
\hline 3.017 & HJ & 60.8 & 66.3 & 12.5 \\
\hline 3.086 & SHDH5 & 53.8 & & \\
\hline
\end{tabular}

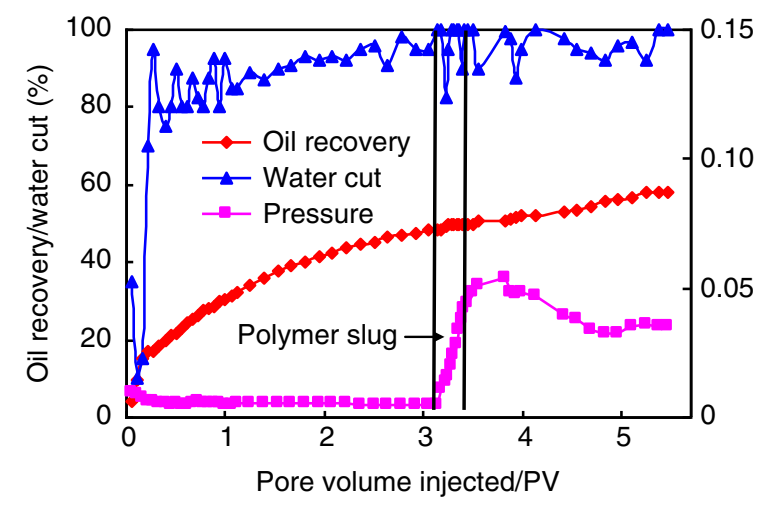

Figure 3

Polymer flooding curve of SHDH5 in the homogeneous sandpack model. (Permeability: $1.835 \mu^{2}$ ).

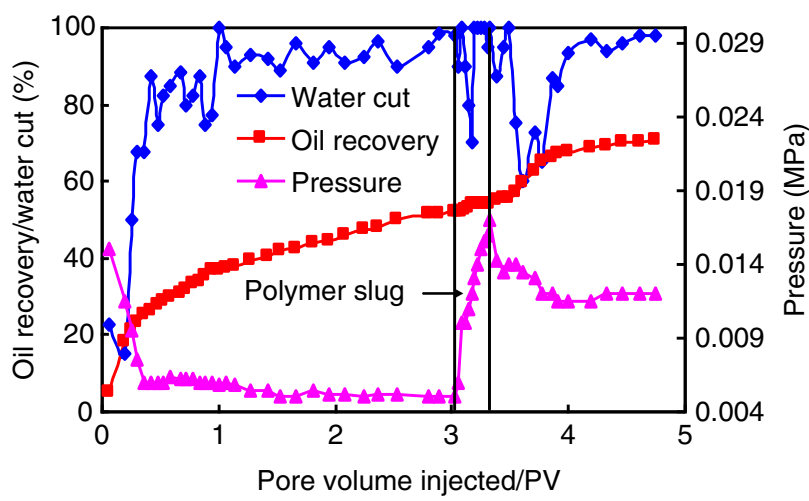

Figure 4

Polymer flooding curve of $\mathrm{HJ}$ in the homogeneous sandpack model. (Permeability: $1.697 \mu \mathrm{m}^{2}$ ). shown in Figures 3 and 4. Although the pressures of SHDH5 polymer flooding and subsequent water flooding are higher than those of $\mathrm{HJ}$, the decreased degree of water cut and tertiary oil recovery of HJ are high than those of SHDH5. In the homogeneous model, significant improvement of the water injection profile is not required. So, compared with HPAM, HAPAM has no advantage for polymer flooding. The great retention loss of HAPAM can cause a reduction in the amount of movable polymer through porous media, which will cause a decrease in effective viscosity and lead to low tertiary oil recovery.
However, in the heterogeneous model, the oil displacement effect of SHDH5 has some improvement. The heterogeneous model was simulated by two parallel sandpacks $(\Phi 2.5 \times 20 \mathrm{~cm})$ with different permeabilities. A summary of the polymer flood tests in the heterogeneous model is shown in Table 4 . The tertiary oil recovery of SHDH5 $(23.8 \%)$ is higher than that of HJ (15.7\%) when the permeability ratio is approximately 2.8 . In these conditions, the curves of polymer flooding are shown in Figures 5 and 6. In the conditions of a certain permeability ratio, the strong retention properties of HAPAM can only adjust the interlayer heterogeneity. 
TABLE 4

Summary of polymer flood tests in the heterogeneous sandpack model

\begin{tabular}{c|c|c|c|c|c}
\hline Polymer & $\begin{array}{c}\text { Permeability } \\
\left(\mu \mathrm{m}^{2}\right)\end{array}$ & Permeability ratio & $\begin{array}{c}\text { Recovery of water } \\
\text { flood }(\%)\end{array}$ & $\begin{array}{c}\text { Final oil recovery } \\
(\%)\end{array}$ & $\begin{array}{c}\text { Tertiary recovery } \\
(\%)\end{array}$ \\
\hline SHDH5 & $3.57 / 1.28$ & 2.79 & 24.6 & 48.4 & 23.8 \\
\hline HJ & $3.39 / 1.17$ & 2.90 & 32.8 & 54.1 & 15.7 \\
\hline SHDH5 & $2.26 / 1.26$ & 1.79 & 40.2 & 58.9 & 20.4 \\
\hline HJ & $2.34 / 1.28$ & 1.83 & 38.5 & 53.4 & 12.5 \\
\hline SHDH5 & $5.43 / 1.13$ & 4.81 & 40.9 & 52.6 & 17.2 \\
\hline HJ & $5.43 / 1.13$ & 4.81 & 35.4 & & 5 \\
\hline
\end{tabular}

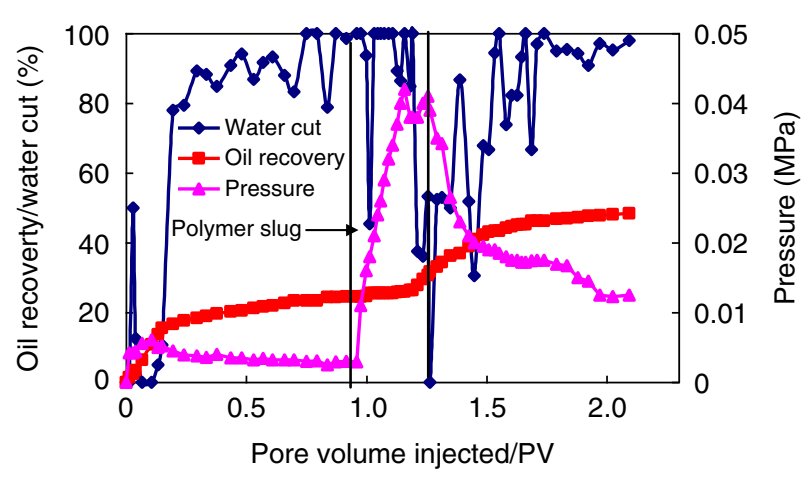

Figure 5

Polymer flooding curve of SHDH5 in the heterogeneous sandpack model. (Permeability ratio: $2.79 \mu \mathrm{m}^{2}$ ).

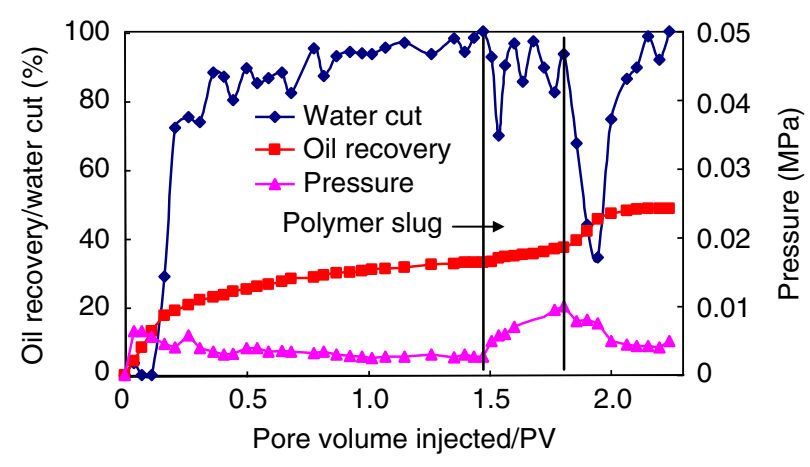

Figure 6

Polymer flooding curve of $\mathrm{HJ}$ in the heterogeneous sandpack model. (Permeability ratio: $2.90 \mu \mathrm{m}^{2}$ ).

It is similar to profile control, which diverts the fluids to improve oil recovery.
However, when the permeability ratio is approximately 1.8 or 4.8 , the tertiary oil recovery of SHDH5 is lower than that of HJ. While the permeability ratio is small (about 1.8), it is similar to the homogeneous model. The great retention loss of HAPAM causes a decrease in effective viscosity, which leads to low tertiary oil recovery. While the permeability ratio is low, more associative polymer are injected into the low-permeability sandpack. Plugging due to strong retention tends to inhibit flow through low-permeability regions, therefore reducing the sweep of the injectant and tertiary oil recovery. While the permeability ratio is high (about 4.8 ), the polymer and subsequent water flooding tend to flow through the high-permeability sandpack. The displacing fluid cannot spread to the low-permeability sandpack with more residual oil, which leads to low tertiary oil recovery. The ability to enhance oil recovery of the two kinds of polymers in the heterogeneous model of high and low permeability is shown in Table 5. While the permeability ratio is approximately 1.8 or 4.8 , the results indicate that the contribution of HAPAM to tertiary recovery of the low-permeability sandpack is very small (4.6-5.6\%). Therefore, HAPAM may damage the low-permeability layer due to its strong retention properties.

\subsection{Microstructures in Porous Media}

The microstructures of the two kinds of polymers in porous media are shown in Figures 7-10. Figures 7 and 8 show micrographs of the conventional polymer HJ and associative polymer SHDH5 at the inlet of the core, respectively. The micrograph of HPAM has no significant difference compared with that of HAPAM. It is because both kinds of polymers have a large retention capacity at the inlet of the core. The polymer flakily adheres to the surface of the rock. The network structure 
TABLE 5

Ability to enhance oil recovery in the heterogeneous sandpack model of high and low permeability

\begin{tabular}{|c|c|c|c|c|c|}
\hline Polymer & $\begin{array}{l}\text { Permeability } \\
\qquad\left(\mu \mathrm{m}^{2}\right)\end{array}$ & Permeability ratio & $\begin{array}{l}\text { Recovery of water } \\
\text { flood }(\%)\end{array}$ & $\begin{array}{l}\text { Final oil recovery } \\
(\%)\end{array}$ & $\begin{array}{c}\text { Tertiary recovery } \\
(\%)\end{array}$ \\
\hline \multirow[t]{2}{*}{ SHDH5 } & High 3.57 & \multirow[t]{2}{*}{2.79} & 46.6 & 66.9 & 20.3 \\
\hline & Low 1.28 & & 0.5 & 28.1 & 27.6 \\
\hline \multirow[t]{2}{*}{ HJ } & High 3.39 & \multirow[t]{2}{*}{2.90} & 57.0 & 77.9 & 20.9 \\
\hline & Low 1.17 & & 7.8 & 18.3 & 10.5 \\
\hline \multirow[t]{2}{*}{ SHDH5 } & High 2.26 & \multirow[t]{2}{*}{1.79} & 40.3 & 63.6 & 23.3 \\
\hline & Low 1.26 & & 40.0 & 44.6 & 4.6 \\
\hline \multirow[t]{2}{*}{$\mathrm{HJ}$} & High 2.34 & \multirow[t]{2}{*}{1.83} & 38.2 & 68.4 & 30.2 \\
\hline & Low 1.28 & & 38.8 & 48.9 & 10.1 \\
\hline \multirow[t]{2}{*}{ SHDH5 } & High 5.43 & \multirow[t]{2}{*}{4.81} & 46.6 & 63.2 & 16.6 \\
\hline & Low 1.13 & & 27.8 & 33.4 & 5.6 \\
\hline \multirow[t]{2}{*}{$\mathrm{HJ}$} & High 5.43 & \multirow[t]{2}{*}{4.81} & 58.7 & 76.0 & 17.3 \\
\hline & Low 1.13 & & 13.0 & 30.9 & 17.9 \\
\hline
\end{tabular}

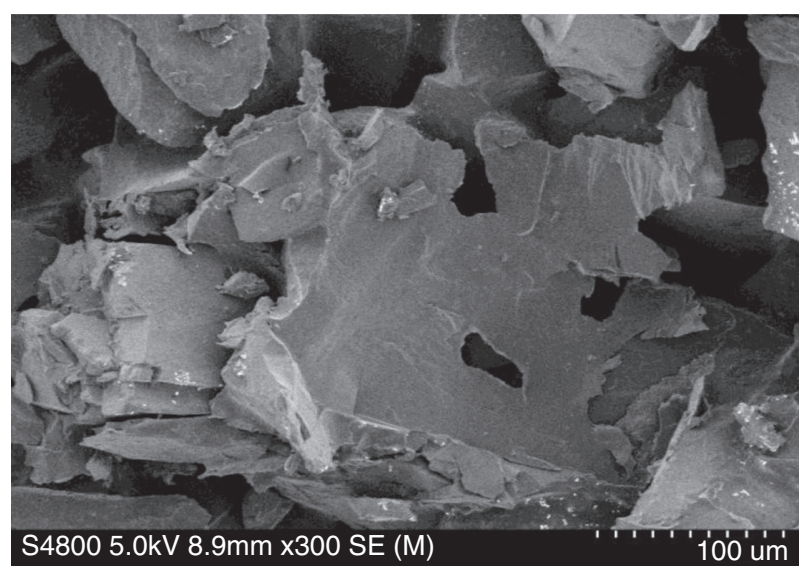

Figure 7

The microstructure of $\mathrm{HJ}$ in the inlet of the core.

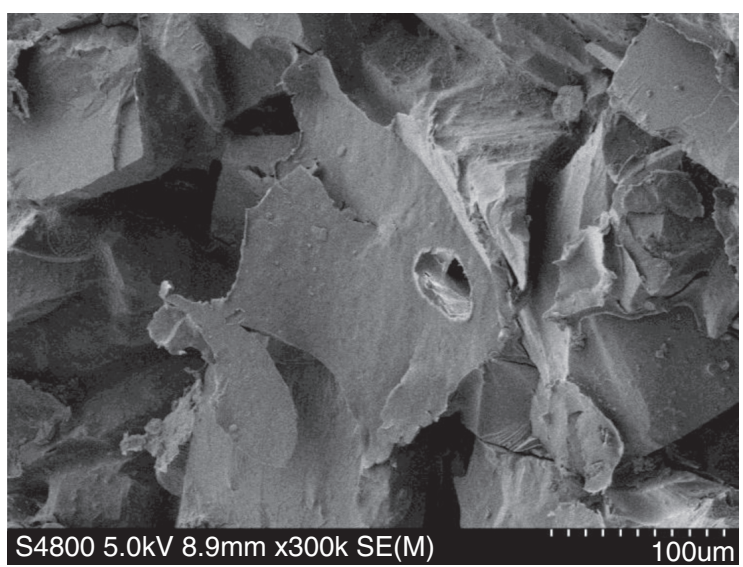

Figure 8

The microstructure of SHDH5 in the inlet of the core. of the polymer cannot be observed at the inlet of the core. However, in the middle of the core, the micrographs of the different polymers are very different, as shown in Figures 9 and 10.

It can be seen that both polymers can form networks in the middle of the core. However, the networks of HPAM are larger and more integrated than those of
HAPAM. The diameter of the HPAM skeleton is significantly larger than that of HAPAM. This is likely because the retention loss of HAPAM is greater than that of HPAM, causing a reduction in the amount of movable polymer chains in the pores, which produces a defective and small network and leads to a decrease in effective viscosity and ability to enhance oil recovery. 


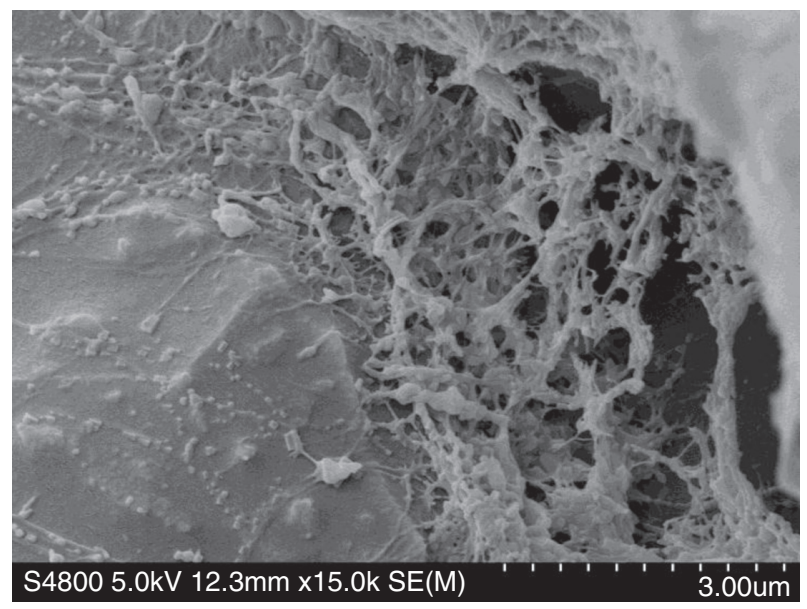

Figure 9

The microstructure of $\mathrm{HJ}$ in the middle of the core.

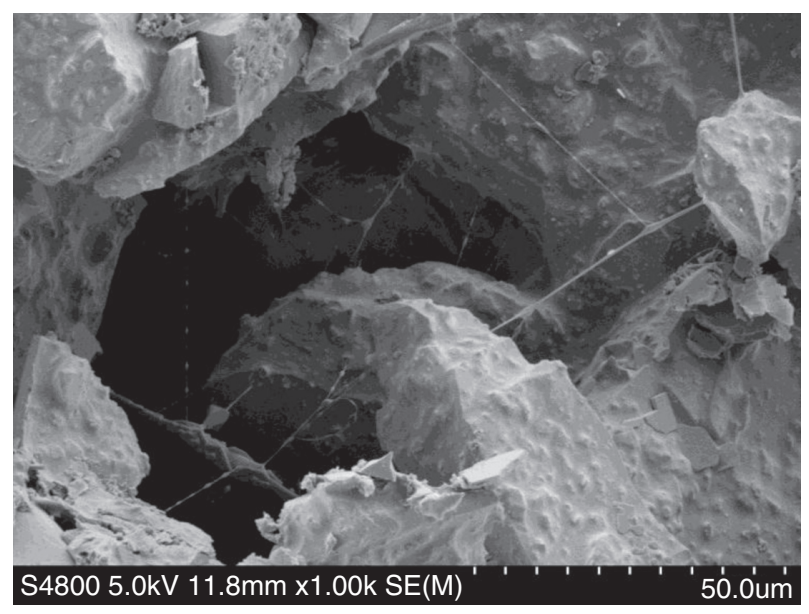

Figure 10

The microstructure of SHDH5 in the middle of the core.

\section{CONCLUSIONS}

Under certain conditions, HAPAM can establish a higher resistance factor and residual resistance factor. This is because the dynamic retention capacity of HAPAM is greater than that of HPAM. For the same reason, the effective viscosity of HAPAM is lower than that of HPAM. However, high flow resistance is not an advantage for polymer flooding in the homogeneous model. The oil displacement efficiency of HAPAM is always lower than that of HPAM for different permeabilities $\left(0.5-3.0 \mu \mathrm{m}^{2}\right)$ at the same concentration of
$2000 \mathrm{mg} / \mathrm{L}$. Only in the heterogeneous model and at a suitable permeability ratio (about 2.8 ) is the tertiary oil recovery of HAPAM higher than that of HPAM. Thus, the application of HAPAM in polymer flooding has some limitations.

\section{ACKNOWLEDGMENTS}

This work was sponsored by the National S\&T Major Project (Grant No.: 2011ZX05024-004) on chemical flooding for offshore heavy oil fields, and "Taishan Scholars" Construction Engineering (No. ts20070704).

\section{REFERENCES}

1 Zhong C.R., Huang R.H., Xu J.Y. (2008) Characterization, solution behavior, and microstructure of a hydrophobically associating nonionic copolymer, J. Solution Chem. 37, 1227-1243.

2 Shashkina Y.A., Zaroslov Y.D., Smirnov V.A., Philippova O.E., Khokhlov A.R., Pryakhina T.A., Churochkina N.A. (2003) Hydrophobic aggregation in aqueous solutions of hydrophobically modified polyacrylamide in the vicinity of overlap concentration, Polymer 44, 2289-2293.

3 Feng Y., Luo P., Luo C., Yan Q. (2002) Direct visualization of microstructures in hydrophobically modified polyacrylamide aqueous solution by environmental scanning electron microscopy, Polym. Int. 51, 931-938.

4 Gao B.J., Wu N., Li Y.B. (2005) Interaction between the strong anionic character of strong anions and the hydrophobic association property of hydrophobic blocks in macromolecular chains of a water-soluble copolymer, J. Appl. Polym. Sci. 96, 714-722.

5 Gouveia L.M., Paillet S., Khoukh A., Grassl B., Müller A. J. (2008) The effect of the ionic strength on the rheological behavior of hydrophobically modified polyacrylamide aqueous solutions mixed with sodium dodecyl sulfate (SDS) or cetyltrimethylammonium $p$-toluenesulfonate (CTAT), Colloids Surf. A. Physicochem. Eng. Aspects 322, 211-218.

6 Taylor K.C., Nasr-El-Din H.A. (1998) Water-Soluble Hydrophobically Associating Polymers for Improved Oil Recovery: A literature review, J. Petrol. Sci. Eng. 19, 265-280.

7 Taylor K.C., Nasr-El-Din H.A. (2007) Hydrophobically Associating Polymers for Oil Field Applications, Petroleum Society's 8th Canadian International Petroleum Conference (58th Annual Technical Meeting), Calgary, 12-14 June.

8 Kun R., Jinlan W., Meiqin L., Chunming X. (2006) Rheological Properties of Hydrophobically Associating Polyacrylamide Solution, Petrol. Sci. 3, 66-72.

9 Lu H., Feng Y., Huang Z. (2008) Association and Effective Hydro-dynamic Thickness of Hydrophobically Associating Polyacrylamide Through Porous Media, J. Appl. Polym. Sci. 110, 1837-1843. 
10 Maia A.M.S., Borsali R., Balaban R.C. (2009) Comparison between a Polyacrylamide and a Hydrophobically Modified Polyacrylamide Flood in a Sandstone Core, Mater. Sci. Eng. 29, 505-509.

11 Argillier J.F., Audibert A., Lecourtier J., Moan M., Rousseau L. (1996) Solution and adsorption properties of hydrophobically associating water-soluble polyacrylamides, Colloids Surf. A. Physicochem. Eng. Aspects 113, 247-257.

12 Volpert E., Selb J., Candau F., Green N., Argillier J.F., Audibert A. (1998) Adsorption of hydrophobically associating polyacrylamides on clay, Langmuir 14, 1870-1879.

13 Zhang C., Ye Z., Shi L., Zhao W., Zhang Z. (2007) A study on the mechanism to build flow resistance by hydrophobic associated polymer, China Offshore Oil Gas. 19, 4, 251-253 (China).

14 Ye Z., Jia T., Shi L., Chu Y., Shu Z. (2007) The mobility control capacity of hydrophobic associating polymer in high permeability porous media, J. Southwest Petroleum University 29, 100-104 (China).

15 Wang J., Luo P.Y., Zhang G.Q. (2001) The flow properties of aqueous solution of hydrophobically associating amphoteric polymer NAPs through porous media, Oilfield Chem. 18, 152-154 (China).
16 Wang J., Dong M. (2009) Optimum effective viscosity of polymer solution for improving heavy oil recovery, J. Petrol. Sci. Eng. 67, 155-158.

17 Buchgraber M., Clemens T., Castanier L.M., Kovscek A. R. (2009) The Displacement of Viscous Oil by Associative Polymer Solutions, SPE ATCE Annual Conference and Exhibition, New Orleans, 4-7 Oct.

18 Dupuis G., Rousseau D., Tabary R., Grassl B. (2011) Flow of Hydrophobically Modified Water-Soluble-Polymer Solutions in Porous Media: New Experimental Insights in the Diluted Regime, SPE J. 16, 43-54.

19 Lv K., Dai C.L., Zhang R.R., Liu X.Z., Zhang J., Tang E.G. (2010) Investigations of Adsorption Rules of Hydrophobically Associating Polymer in the Porous Medium, Oilfield Chem. 27, 391-394 (China).

Cite this article as: P. Zhang, Y. Wang, Y. Yang, W. Chen and S. Bai (2013). Effective Viscosity in Porous Media and Applicable Limitations for Polymer Flooding of an Associative Polymer, Oil Gas Sci. Technol 70, 6, 931-939. 